\title{
7 Facing COVID-19 in rural Honduras: experiences of an indigenous women's association
}

\author{
Alfredo Reyes, Hazel Velasco, Mercedes \\ García, and Olga Pérez
}

\section{Positionality}

Given current events, and as Central American researchers, we are committed to highlighting the impacts of the COVID-19 pandemic in our region, especially in those communities that were already in a vulnerable situation as a result of the economic and social inequities that characterize our countries. After working for almost six years in the rural areas of western Honduras, mainly with the Lenca ethnic communities and specifically with women farmers, one of our first thoughts was: how will the pandemic impact those smallholders' livelihoods?

In this chapter, we seek to present the experiences, struggles, and tactics of Lenca women to cope with the pandemic's effects. At the same time, Alfredo and Hazel recognize their limitations by not being part of these communities and being currently outside the region. Therefore, we decided to write together with the Association of Renewed Intibucan Women (AMIR) to develop a narrative that prioritizes their voices, experiences, and perceptions. AMIR is a grassroots association of indigenous Lenca women that possesses a long history of advocacy for women's rights throughout the communities of the municipality of Intibucá in Honduras. Thus, the members of this organization hold the insiders' knowledge to understand the struggles faced and strategies implemented by their members throughout the pandemic.

\section{A pre-COVID-19 glance at the smallholders' horticultural producers in rural Honduras}

The communities in western Honduras rely on agriculture and their harvests' commercialization in the surrounding urban areas as their main livelihood. 
In the case of the Lenca populations that inhabit the department of Intibucá, their products consist mainly of fruit and vegetables, which are quickly perishable. Also, the communities lack adequate storage infrastructure, and in some cases, no electricity is available to maintain the cold chain needed to extend the crops' lives. These challenges force smallholder farmers to transport their products to the sale sites as soon as possible. Most households in the area are small vegetable producers who typically lack formal safety nets, such as agricultural insurance or access to emergency funds (Sanders, 2019), which significantly limits their ability to respond to external shocks, such as a pandemic. Additionally, traditional gender roles in the region limit women's ability to acquire and control productive assets or access formal financial services and education (Larson, Castellanos, and Jensen, 2019). These factors impact their bargaining power within the household, which leaves them even more vulnerable to potential crises.

In general terms, vegetable marketing in the Intibucá is carried out in three main ways. The best quality vegetables are commercialized either through producers' associations or through intermediaries; in both instances, the product is distributed to supermarkets in the country's main cities. Men usually receive the payment for those sales, and, therefore, they decide on the destination of that income. On the other hand, lower-quality vegetables are sold in local markets, and women are usually responsible for those sales and are the ones who determine what to do with that income.

\section{The Lencas and Asociación de Mujeres Intibucanas Renovadas (AMIR)}

The Lencas are the largest indigenous group in Honduras, comprising 63 percent of total ethnic groups and 6 percent of the Honduran population (INE, 2013). Their distribution is concentrated in western Honduras, where more than 90 percent of the Lenca population live in the Departments of Intibucá, La Paz, and Lempira (INE, 2013). In the areas where the Lencas are found, rural and indigenous populations suffer alarming levels of poverty and malnutrition. Moreover, 72 percent of indigenous households, compared to 41.6 percent of households nationwide, cannot cover the basic food-basket costs, which places them on the extreme poverty line (CADPI, 2017). Due to the adverse socioeconomic conditions indigenous communities face, western Honduras has become a focus of international development organizations during the last 20 years. The efforts to support these populations have focused on shifting their production systems by integrating more efficient practices and introducing high-value crops like horticulture or coffee. Thus, development agencies have reinforced this strategy as a means to fight poverty and food insecurity levels in the area. 
In this context, AMIR emerged in 1980 as an indigenous women's grassroots organization focused on improving its members' and families' lives. The organization started focusing on human rights and empowerment but has expanded to other topics including food security, sustainable agriculture, and food processing. At present, AMIR has an active membership of about 450 women distributed across 28 community-based groups. They provide their members' technical assistance in maize, beans, fruits, and vegetables. AMIR members are also trained to establish home gardens and food processing (Figure 7.1), and they can request loans to establish productive crops such as strawberries and potatoes.

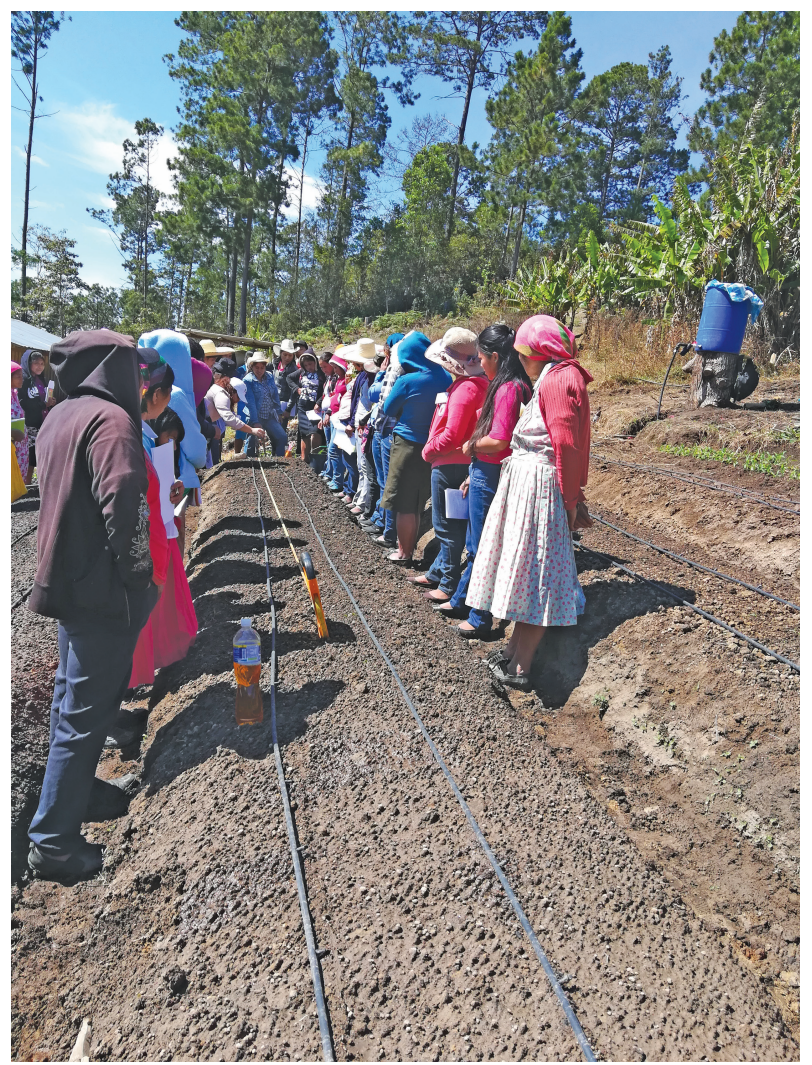

Figure 7.1 Prior to the COVID-19 pandemic, AMIR members participate in a Farmer Field School about biointensive home gardens ${ }^{1}$ in the community of Malguara, Intibucá, Honduras (Alfredo Reyes). 
AMIR also has a processing plant that receives and purchases its members' fruit to transform it into wines, sweets, jams, and preserves. The plant has functioned as a mechanism to ensure the sale of women's products and provide them with an income option within their households. AMIR products are sold locally under the "Siguatas Lencas" brand.

\section{National and local context during the pandemic}

In the next section, we take a look at the short-term direct and indirect effects that the COVID-19 pandemic had on the Lenca communities served by AMIR. Additionally, we cover the events one year after the pandemic first entered Honduras and the combined effects of the Eta and Iota hurricanes.

On March 16, 2020, with eight confirmed cases of COVID-19 in the country, the government of Honduras issued the first statement restricting the movement of people and requested the indefinite closure of non-essential businesses nationwide (UNAH, 2020). Local government relied on the military and the police to enforce the measures and deployed agents on the main highways, to deter and arrest offenders.

In parallel, at a community level, residents in Intibucá rural areas established mesas de seguridad (security councils), which regulated neighbors' movement and although they did not have the power to penalize those who did not comply with the community quarantine, they were supported by the police to enforce the law. Besides, the few COVID-19 reported cases in the rural communities of Intibucá were linked to intermediaries moving agricultural products to the cities. This narrative reinforced the urgency to stop all types of mobility and led to the blockade of roads for almost two months.

The state of Honduras enforced restrictive mobilization measures, and their severity changed as the COVID-19 cases increased or decreased. In this way, when a decrease in infections was reported, the measures were relaxed, and when the cases were increasing, the restriction measures were reestablished. The state of Honduras used the license plates and personal identification numbers to limit the number of people circulating in public spaces. The measure that persisted without distinction between urban and rural areas was controlling the circulation of citizens through their identification card number, allowing people to leave their homes every 15 days for personal chores, such as grocery shopping or banking.

Most of these restrictive measures were lifted when two consecutive Hurricanes hit Honduras. First Eta, a Category 4 hurricane, entered Honduran territory on November 3, 2020, followed two weeks later by Iota, a Category 5 hurricane. In Honduras, the negative impacts of both hurricanes mostly occurred along the north coast. The floodwaters inundated wide areas of northern Honduras, including entire communities 


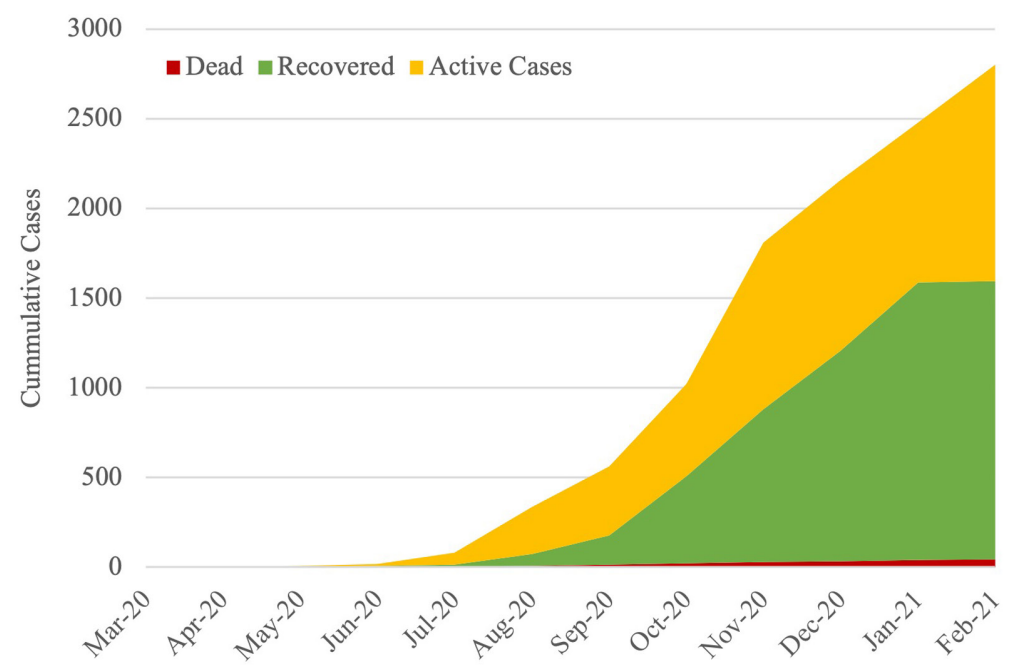

Figure 7.2 COVID-19 Cumulative cases in Intibuca, Honduras (Sinager, 2021).

and San Pedro Sula International Airport. Nonetheless, the continuous rain from both storms affected the electricity service, roads, and crops nationwide.

To date, the number of COVID-19 cases in the Department of Intibucá has increased (Figure 7.2), with the vast majority reported as occurring in urban areas. However, when compared with the rest of the country the number has remained low, with 1,433 active cases reported by February 2021. The evidence of COVID-19 cases in the rural areas of Intibucá is mainly anecdotal, such as when a relative in severe health conditions must be transported to be treated at the public hospital at la Esperanza Town.

\section{The short-term effects of the COVID-19 pandemic on agriculture and rural women}

The consequences of the movement restrictions on the agricultural sector were evident almost immediately. For example, during the first months of quarantine, households were unable to sell their products outside the community, which significantly reduced their incomes. Many smallholders lost most of the harvest, especially those households dedicated to the production of vegetables and potatoes. Regarding these events, one of AMIR members explained that: 
The quarantine has affected us severely because we hoped to sell our vegetables, and we could not. Many families invested and took out loans but could not generate income. We were unable to sell most of the harvest, and even what we sold was not at the expected price. The biggest problem now is that people have run out of working capital. In this new planting cycle, we see more corn being planted because the investment is low.

Furthermore, AMIR members have expressed that, although intermediaries can now transit between communities, households do not have products to sell because they were unable to replant their fields or to provide the required quantities. Moreover, the Honduran government announces and extends the containment measures weekly, which gives producers insufficient time for planning and seeking alternatives.

In the case of women, the pandemic has made it impossible for them to mobilize to sell their products in the city of La Esperanza. As previously mentioned, this marketing channel has been essential for women in the area and their ability to generate income. Additionally, in the case of AMIR members, the restrictions coincided with the highest fruit-production period. In previous years, AMIR trained and supported its members on the establishment of fruit crops such as peaches, strawberries, and blackberries that are bought by AMIR's processing plant to be transformed into wines, jams, and sweets. The income generated by these sales have become relevant for AMIR members' livelihoods.

\section{Strategies implemented by AMIR and its members}

To face the new economic difficulties in the face of COVID-19 in combination with government measures, AMIR members have used different strategies. At the community level, women have organized to sell and exchange available crops and products:

People who had vegetables exchanged with those who had cheese or eggs. Inside the communities, neighbors started to move the products as they were needed; the groceries that usually came from the city became scarce. For example, the stores ran out of bakery products, and women started making bread to sell, and that is how they are finding other options.

Moreover, AMIR members who had established home gardens had a variety of crops to meet household needs and, in some cases, they were able to sell or trade with their neighbors. For AMIR's staff, the pandemic represents an 


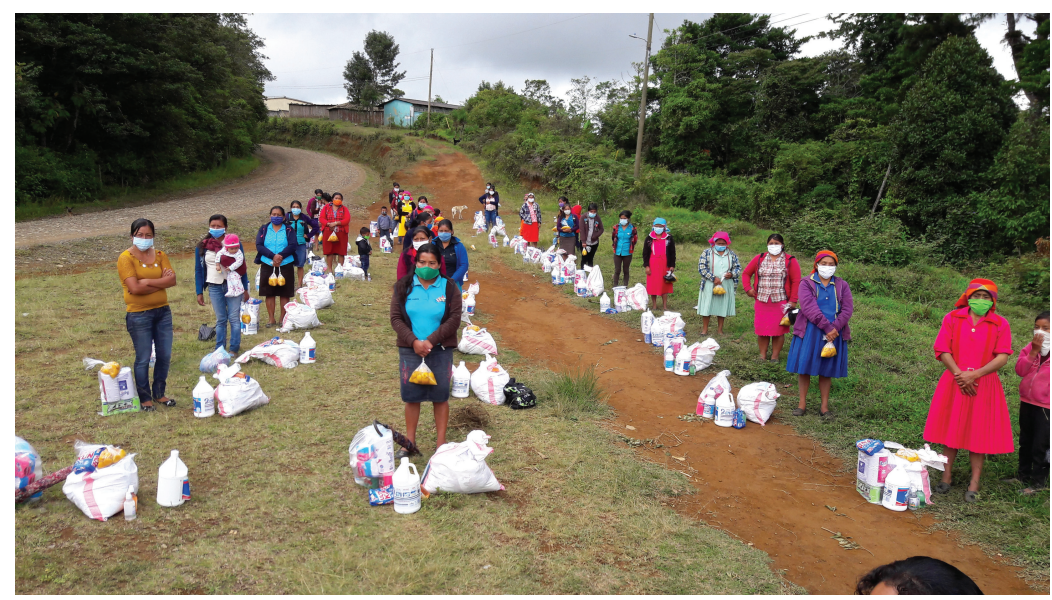

Figure 7.3 AMIR delivers food and cleaning kits in the community of Planes Río Grande, Intibucá, Honduras (AMIR).

event that can strengthen their connections with international cooperation and an opportunity to seek projects that can benefit their members. As part of their actions, AMIR negotiated a new project with OXFAM Honduras and was also able to reallocate funds from an existing initiative with the Inter-American Foundation. These initiatives have allowed them to deliver food and cleaning kits to 436 households (each kit valued at 1,000 lempiras or approximately USD 40) and 1,000 lempiras cash bonuses to 400 members. The delivery of the bonuses in the form of cash was an essential decision since it considers that each woman has different needs. AMIR currently has 450 active members (Figure 7.3).

AMIR staff resumed their activities and field visits by June 2020. They have used WhatsApp and "short message service" (SMS) as their main communication channel to organize workshops. During their field visits, they work with small groups in open spaces to keep their members safe. They have tried delivering workshops via Zoom, but insufficient connection in rural areas has rendered this option ineffective (Figure 7.4).

\section{One year and two hurricanes}

After a year of living with the pandemic, maintaining the security measures has become a daily challenge for the Lenca communities. As presented in the previous section, the pandemic's initial effects directly affected the 


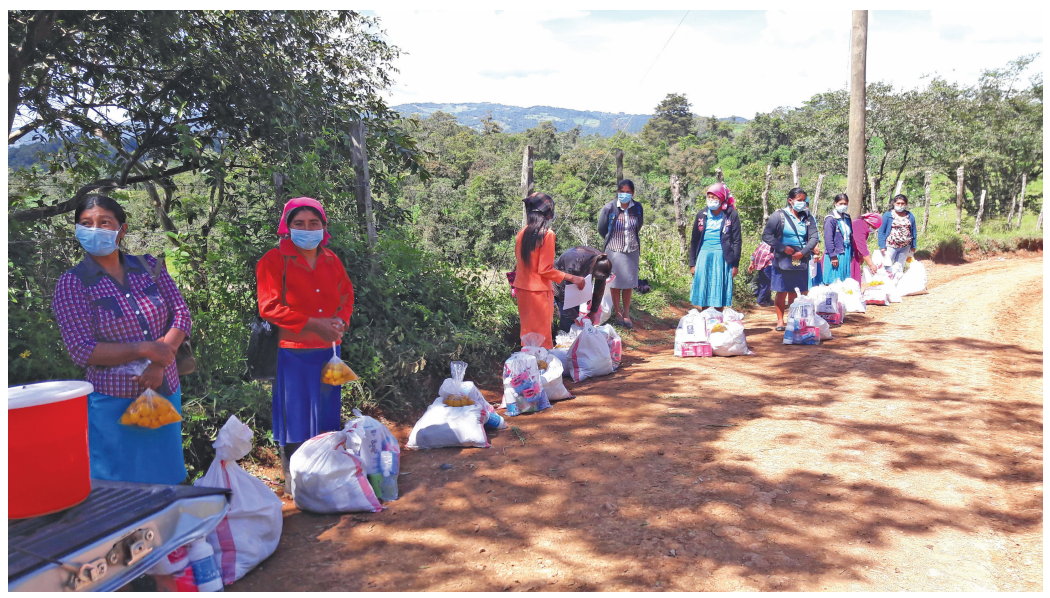

Figure 7.4 AMIR delivers cleaning kits and cash bonuses in the communities, Intibucá, Honduras (AMIR).

commercialization of agricultural products from rural areas to urban centers. As mobility restrictions were lifted, those who had products available continued to be affected by transportation availability. When transportation was restored, the mayor's office tried to limit passenger numbers within the transportation units, which was not a sustainable option for either the bus owners nor their passengers. The buses started to run at full capacity, thus limiting the space available to transport agricultural products.

During this time, AMIR focused on providing biosafety kits that include masks and alcohol gel, but not in the capacity to supply all its members and their families. In this sense, an AMIR member mentioned that:

For us, it is costly to be buying masks when we have to cover other needs. When we travel on the buses, we reuse the masks that AMIR has given us, but not all people have the means to wear face protection or follow all the security measures.

Traveling to urban areas is still a necessity that people cannot avoid as it continues to be the main market for agricultural products and the only place where they can get inputs for their production. The consecutive arrival of Hurricanes Eta and Iota at the end of 2020 increased the difficulties experienced in the area due to the pandemic. The communities of Río Grande, Mixcure, Azacualpita, Yamaranguila, and Belén were among the most 
affected. Once again, transport between rural communities and the urban area was interrupted by landslides that blocked the roads.

On the other hand, the communities were preparing for the harvest of second-season corn and beans. An AMIR member reported that:

We had already folded the corn and were waiting for it to finish drying to start the harvest. That is when the rain came that did not stop for several days, the corn was nacido (covered with fungi), and we lost the entire harvest. Due to the amount of water, the beans were also ruined.

Intercropping corn and beans is part of AMIR's initiative to rescue indigenous cultivation practices and strengthen its members' food security. The initiative was accompanied by a seed bank and grain storage to be created with the harvest. In addition to corn, AMIR members lost their vegetable crops and fruit that were part of the home garden program that the association has been promoting.

After the hurricanes impacted the area, AMIR staff changed its role into delivering humanitarian aid. They visited the most affected communities to deliver food, biosafety, and hygiene equipment, blankets, and clothing for women and girls. AMIR has focused on capitalizing on its network with international NGOs to access new projects and funding to support their members. Based on last year's experiences, they shifted their approach to strengthening their members' resiliency by focusing on the development of a revolving fund, the establishment of irrigation systems and home gardens, the rescue of the milpa, support of entrepreneurship initiatives, the acquisition of land for collective use, and the creation of a seed and grain bank.

\section{Future considerations}

It is difficult to predict the pandemic's long-term impacts on Lenca women and their households. Although the restriction measures have been effective in avoiding contagion in the area, they have jeopardized the sustainablilty of small producers' livelihoods.

In terms of the immediate effects, we have evidenced drastic changes in the preferred crop choices. Households have increased planting corn and beans since they require low investment and are easy to store; however, they have low economic value. The transition to basic grains and monoculture can harm households by reducing their income. Nonetheless, in the long term, these changes can have a profound impact by limiting the diversity of available agricultural products in the communities and increasing their vulnerability to other threats such as climate change. 
Furthermore, it will also be necessary to explore how these decisions are made within households and how women's positions and power in the household will be impacted, particularly after evidencing how their income sources have been affected. Additionally, in the face of external shocks, evidence suggests that women's assets, such as small farm animals, are the first to be liquidated (Quisumbing, Kumar, and Behrman, 2018).

Although AMIR members expressed concern about the future and the evident reduction of income in their households, they also consider that the restrictive measures have been necessary:

We are here [in the community] because we are afraid of getting sick, not because we have been locked up. We prefer to stay at home, even if we lack something, instead of going out and risking getting sick or making our family sick.

\section{Note}

1 The WAgN: Honduras project included a research and extension team from the Pennsylvania State University and Zamorano University, with funding from USAID's Feed the Future Horticulture Innovation Lab at UC Davis, and partnered with AMIR to implement gender-integrated Farmer Field Schools.

\section{References}

CADPI (2017) Nota ténica de país sobre cuestiones de los pueblos indigenas: República de Honduras.

Instituto Nacional de Estadísticas (2013) Censo: XVII Censo de Población y VI de Vivienda. Tegucigalpa, Honduras.

Larson, J. B., Castellanos, P. and Jensen, L. (2019) 'Gender, household food security, and dietary diversity in western Honduras', Global Food Security, 20, pp. 170-179. doi:10.1016/j.gfs.2019.01.005.

Quisumbing, A. R., Kumar, N. and Behrman, J. A. (2018) 'Do shocks affect men's and women's assets differently? Evidence from Bangladesh and Uganda', Development Policy Review, 36(1), pp. 3-34. doi:10.1111/dpr.12235.

Sanders, A. (2019) Assembling the Horticulture Value Chain in Western Honduras. Penn State University.

SINAGER (2021) Coronavirus COVID-19 En Honduras. Available at: https:// covid19honduras.org/ (Accessed: March 8, 2021).

UNAH (2020) Cronología de la pandemia Covid 19 en Honduras. Available at: https://mdd.unah.edu.hn/publicaciones/cronologia-de-la-pandemia-covid-19-en -honduras (Accessed: August 3, 2020). 